\title{
Extracorporeal shock wave therapy in the management of insertional Achilles tendinopathy: the ASSERT database
}

\author{
Gayle Maffulli ${ }^{1}$ \\ Johnny Padulo 2,3 \\ Enzo luliano ${ }^{2}$ \\ Amol Saxena 4 \\ Jan Rompe ${ }^{5}$ \\ Nicola Maffulli6,7 \\ 1 Wholelife Clinics, London, UK \\ 2 University eCampus, Novedrate, Italy \\ ${ }^{3}$ Faculty of Kinesiology, University of Split, Split, \\ Croatia \\ ${ }^{4}$ Department of Sports Medicine, Palo Alto Medical \\ Foundation, Palo Alto, CA, USA \\ 5 OrthoTrauma Evaluation Institute, Mainz, Germany \\ 6 Department of Musculoskeletal Disorders, Faculty of \\ Medicine and Surgery, University of Salerno, Salerno, \\ Italy \\ 7 Centre for Sports and Exercise Medicine, Barts and \\ the London School of Medicine and Dentistry, Mile \\ End Hospital, London, UK
}

Corresponding author:

Nicola Maffulli

Department of Musculoskeletal Disorders

School of Medicine and Surgery

University of Salerno,

Mary University of London

Barts and the London School of Medicine and Dentistry

Centre for Sports and Exercise Medicine

Mile End Hospital 275 Bancroft Road

E1 4DG, London, England, UK

Tel.: +447989358279

E-mail: n.maffulli@qmul.ac.uk

\section{Summary}

Introduction: The present study determined the effectiveness of extracorporeal shock wave therapy (ESWT) in patients suffering from insertional Achilles tendinopathy over a 24-month period.

Methods: Participants were recruited by different clinicians of the National Health Service (NHS) and private sector centres in the UK. The data of participants were collected in the ASSERT database (Assessment of the Effectiveness of ESWT for Soft Tissue Injuries). The 80 partici- pants (average age 53.41 y; range 20-81 y) underwent a standardized ESWT protocol, and different outcome measures were collected at baseline and again after 3, 6, 12 and 24 months following ESWT intervention. The outcomes were the VAS, for pain perception, the VAS-A, for the severity of the Achilles tendinopathy in daily life activities, and the 6 scores of EuroQolt 5D, for quality of life.

Results: There was a significant amelioration over time in 5 of the 8 analyzed outcomes (at least $p=0.002$ ) that were VAS, VISA-A, and EQ-5D -3L domains (Mobility, Pain/Discomfort, and Usual Activities scores).

Conclusion: ESWT showed beneficial effects over a 24-month follow-up period when used for the treatment of Insertional Achilles tendinopathy. Level of evidence: IV.

KEY WORDS: Achilles tendinopathy, extracorporeal shock wave therapy, longitudinal study.

\section{Introduction}

Achilles tendinopathy is one of the conditions that causes posterior heel pain. Insertional Achilles tendinopathy (IAT) is a distinct clinical entity from non-insertional Achilles tendinopathy ${ }^{1}$ and it accounts for $20 \%$ to $24 \%$ of all Achilles disorders ${ }^{2}$. The current treatment for IAT varies substantially, and several surgical and non-surgical treatments have been described. However, its management remains controversial and no consensus exists about the most effective treatment ${ }^{1,3}$. Non-surgical intervention is preferred prior to surgical intervention ${ }^{3}$, and it includes rest, activity modification, anti-inflammatory medication, physical therapy, eccentric exercise, and corticosteroid injections ${ }^{4}$. Furthermore, in the last two decades, the effectiveness of extracorporeal shock wave therapy (ESWT) was also investigated. The efficacy of this therapy in the management of IAT seems to be confirmed by several studies. A systematic review of Al-Abbad and Simon ${ }^{5}$ published in the 2013 showed that satisfactory evidence exists concerning the effectiveness of low-energy ESWT in the treatment both of chronic insertional and non-insertional Achilles tendinopathies at a minimum 3 months' follow-up. Similarly, Rompe et al. ${ }^{6}$ showed that low-energy ESWT was more effective than eccentric loading 
in the management of IAT. The use of ESWT do not exclude the additional use of eccentric loading treatment in order to maximise the results: in fact, the combination of ESWT and eccentric loading can show superior results than using each modality alone $^{5}$. Positive results in the management of chronic IAT was obtained also with the high-energy ESWT7 The effectiveness in the treatment of the IAT could be mediated by the enhancement of the neovascularization induced by ESWT ${ }^{8,9}$. Another effect of ESWT demonstrated in animal model is the rapid degeneration of the intracutaneous nerve fibres in the skin ${ }^{10}$ : this degeneration of cutaneous nerve fibres probably mediates the relief of pain produced by ESWT. This confirms the results obtained on patients with persistent symptoms of painful heel pain in whom the lowenergy ESWT produced a reduction of the pain and an improvement of the heel functionality ${ }^{11}$.

Most studies evaluated only one or few aspects of the IAT symptomatology (e.g. pain or functionality). Furthermore, possible variables influencing the efficacy of the ESWT such as age, gender, or participation in previous therapy was not considered.

The ASSERT study evaluated the effectiveness of the ESWT on patients with chronic IAT over a period of 24 months by considering different aspects, namely: (1) the reduction of the clinical severity of symptoms; (2) the relief of pain; and (3) the improvement of the quality of life. Furthermore, this study also aimed to analyse whether differences existed between males and females patients on the effects of ESWT on these three variables, and whether age and involvement in previous treatments could have played a role in influencing ESWT effect.

\section{Materials and methods}

The ASSERT database was created to collect information concerning the effectiveness of ESWT across the UK. The ESWT machines were standardised and a standardized treatment protocol, together with standardised baseline measurements and outcome as- sessment and time points in centres across the UK, were adopted to aid validity ${ }^{12}$.

\section{Recruitment}

Participants were enrolled from both the National Health Service (NHS) and private sector centres in the UK. Clinicians recruited participants presenting with IAT, and for whom ESWT was designated as the treatment choice.

\section{Participants}

Participants were included if they were over the age of 18 and had: a diagnosis of IAT which had been confirmed by the recruiting clinician; undergone a course of conservative therapy which had not been effective in relieving symptoms; been recommended to receive ESWT at one of the recruiting centres; not been diagnosed with inflammatory arthropathy; and demonstrated the ability to give informed consent.

Eighty-two participants were enrolled (52 males; 30 females) and eighty met all the inclusion criteria (51 males; 29 females) and were considered for analysis. Their characteristics are reported in Table I.

This study has been designed and conducted in accordance with the principles of the Declaration of Helsinki and it has been approved by the Local Ethics Committee (11/LO/0253). A written informed consent was obtained by each participant ${ }^{13}$.

\section{Use of ESWT machine}

Standardisation of the machine and the process of administration of ESWT had been agreed to ensure generalisability, consistency, and reproducibility of the results. All clinicians using the Swiss DolorClast device (Electro Medical Systems SA, Nyon, Switzerland) and Storz devices (Storz Medical AG, Tägerwilen, Switzerland) received training and certification to ensure adherence to the proposed protocol. All clinicians followed a standardised method to administer the ESWT ${ }^{14}$. This included delivering an initial 500 sensitising impulses at a low air pressure (1.5 bar of air pressure). This reduces the pain which patients experience during the treatment. Based on patient

Table I. Sample of participants.

\begin{tabular}{|c|c|c|c|}
\hline & \multirow{2}{*}{$\mathbf{n}$} & \multirow{2}{*}{$\begin{array}{l}\text { Age }(y) \\
\text { Means (range) }\end{array}$} & \multirow{2}{*}{$\begin{array}{l}\text { Number of previous treatments } \\
\text { Means (range) }\end{array}$} \\
\hline & & & \\
\hline Participants enrolled & 82 & $53.18(20-81)$ & $1.72(0-6)$ \\
\hline Males & 52 & $52.65(20-78)$ & $1.69(0-6)$ \\
\hline Females & 30 & $54.03(28-81)$ & $1.77(0-4)$ \\
\hline Participants considered for the analyses & 80 & $53.41(20-81)$ & $1.68(0-6)$ \\
\hline Males & 51 & $52.91(20-78)$ & $1.64(0-6)$ \\
\hline Females & 29 & $54.21(28-81)$ & $1.77(0-4)$ \\
\hline
\end{tabular}


feedback, the clinician increased the air pressure to 2.5 bar or above. The total dose of impulses remained constant at 2500 per session, with one session a week for three consecutive weeks, with a maximum gap between treatments of two weeks.

\section{Database}

The ASSERT database is a web based system (www.assert.org.uk) from which the clinician received a study number for each participant ${ }^{12}$. Only unidentifiable information with the patients' study number was entered into the database. Sensitive data is held on secure servers. Following informed consent, the clinician recorded the following information: (1) diagnosis: this was formulated on clinical grounds and some clinicians also used imaging to confirm the diagnosis; (2) area treated/condition presented with; (3) date of presentation of symptoms; (4) date of treatment of ESWT; (5) code for clinicians centre; (6) centre where treatment was administered; (7) previous treatments prior to consultation; (8) side treated; (9) dates when ESWT was administered; (10) baseline scores recorded: EuroQol questionnaire scores (EQ-5D) ${ }^{15}$, VAS for pain ${ }^{16}$, and VISA questionnaire for Achilles tendinopathy (VISA-A $)^{17}$; (11) follow-up scores at 3 , 6, 12 and 24 months post treatment; (12) satisfaction: rated poor, satisfactory, good or excellent; (13) time to effective treatment; (14) recurrence of the condition; (15) complications; and (16) adverse events.

\section{Baseline and follow-up assessments}

After having obtained written informed consent, the treating clinician undertook baseline assessments. The follow-up assessments were instead performed after 3, 6, 12 and 24 months' post treatment. The coordinators of ASSERT undertook all follow-up assessments via email, telephone or post.

\section{Outcome assessment}

The EQ-5D ${ }^{15}$ and VAS for pain ${ }^{16}$ were completed alongside the VISA-A ${ }^{17}$

The EQ-5D is a standardised measure of health status developed by the EuroQol Group to provide a simple, generic measure of health for clinical and economic appraisal. For the present study, the version $3 \mathrm{~L}$ (EQ-5D-3L) was used; that is a simple questionnaire composed by 5 items with a 3-point scale answer for each item, and designed for completion by the person being treated. Each one of the 5 items respectively investigates 5 dimensions of the quality of life that are (1) mobility, (2) self-care, (3) usual activities, (4) pain/discomfort, and (5) anxiety/depression. A score from 1 (best score) to 3 (worst score) is assigned for each dimension. The EQ-5D also includes a scale, named EQ-5D Thermometer Scale, that allows to obtain a global score to generally describe the quality of life of the patient. It consists in a vertical line, $100 \mathrm{~mm}$ in length, anchored by 2 word descriptors at each end, that are "the worst health you can imagine" and "the best health you can imagine". The patient is asked to mark on the line the point that he feels represents his perception of his current health status. The score is from 0 (worst health status) to 100 (best health status), and it is computed by measuring the distance (in $\mathrm{mm}$ ) between the end of the line marked with "the worst health you can imagine" and the mark on the line indicated by the patient.

The VAS for pain (or Visual Analog Scale for pain) is very similar to the EQ-5D Thermometer Scale but it focuses the attention only on the pain perceived by the patient, and not on the overall quality of life. It consists in a horizontal line, $100 \mathrm{~mm}$ in length asked the patient "How severe is your pain today?". The line is anchored by 2 word descriptors at each end, that are "no pain" and "very severe pain". Also in this case, the patient marks on the line the point that he feels represents his current perception of his pain intensity, and the score, from 0 (no pain) to 100 (very severe pain), is computed as the measurement of the distance (in $\mathrm{mm}$ ) between the end of the line marked with "no pain" and the point on the line indicated by the patient.

The VISA-A (Victorian Institute of Sports Assessment) is a validated questionnaire assessing the severity of Achilles tendinopathy. It consists of 10 items evaluating the self-reported perception of pain and the consequent limitation in performing different tasks (e.g. walking, single leg heel raises, etc.). The score, from 0 (high severity) to 100 (no severity), is computed as summation of the score of each item.

\section{Statistical analysis}

Linear Mixed Model analysis (LMM) with maximum likelihood method was performed in order to evaluate the significant effects over time produced by ESWT in the treatment of the IAT. To perform the LMM analysis, 2 fixed factors were considered: Time factor (fixed factor: T0 vs T3 vs T6 vs T12 vs T24) to investigate differences over time, and Gender factor (fixed factor: males $v s$ females) to investigate differences between males and females patients' outputs. The interaction TimexGender was analysed too. The VAS and the VISA-A scores, as well as the 6 scores of the EQ-5D were considered as dependent variables for the analysis. If two or more of the follow-up datasets were missing the patient was excluded. There were 82 patients enrolled ( $N=52$ males; $n=30$ females) and of these 80 were included in the analysis $(n=51$ males; $\mathrm{n}=29$ females).

The age and the number of previous treatments were considered as covariates of the analysis to verify if these factors could have influenced the VAS, VISA-A and EQ-5D scores over time.

Due to the multiple dependent variables, the Bonferroni correction was used adjust the $p$-value. The Bonferroni correction indicate an adjusted $p$-value $<0.006$ for significance.

When a significant effect over time was detected, Bonferroni post-hoc analysis (adjusted for multiple comparison) was used to perform comparisons in pair among the different time of assessments.

All the analyses were performed with the statistical software SPSS 20 (IBM Corporation, Chicago, IL, USA). 


\section{Results}

There was a significant reduction over time of the VAS score $\left(F_{4,172}=23.558\right.$; $\left.p<0.0001\right)$, with no significant differences between the two genders $\left(F_{1,81}=0.674 ; p=0.414\right)$ and in the interaction Time $\times$ Gender $\left(F_{4,172}=0.350 ; p=0.844\right)$.

Concerning the VISA-A scores, there was a significant improvement over time $\left(F_{4,155}=10.023 ; p<\right.$ $0.0001)$, with no significant differences between the two genders $\left(F_{1,78}=1.776 ; p=0.187\right)$ and in the interaction TimexGender $\left(F_{4,155}=0.558 ; p=0.693\right)$.

Concerning the EQ-5D questionnaire domains, the EQ-5D Anxiety/Depression score did not show significant differences both in Time $\left(F_{4,136}=2.644 ; p=0.036\right)$ and Gender $\left(F_{1,63}=0.035 ; p=0.852\right)$, and similarly also in the interaction Time $\times$ Gender $\left(F_{4,136}=2.021\right.$; $p=0.095)$. Significant reduction over time were instead found in the EQ-5D Mobility score $\left(F_{4,161}=4.424 ; p=0.002\right)$, but no significant differences were found between the two genders $\left(F_{1,76}=0.114\right.$; $p=0.737)$ and in the interaction Time $\times$ Gender $\left(F_{4,172}=0.446 ; p=0.775\right)$. A significant reduction over time was found also in the EQ-5D Pain/Discomfort score $\left(F_{4,168}=7.435 ; p<0.0001\right)$, with no significant differences between the two genders $\left(F_{1,75}=1.192\right.$; $p=0.278)$ and in the interaction Time $\times$ Gender $\left(F_{4,168}=1.390 ; p=0.240\right)$. There was a significant reduction over time of the EQ-5D Usual Activities score $\left(F_{4,167}=7.347 ; p<0.0001\right)$, with no significant differences between the two genders $\left(F_{1,75}=3.449\right.$; $p=0.067)$ and in the interaction Time $\times$ Gender $\left(F_{4,167}=0.998 ; p=0.411\right)$. Conversely, the EQ-5D SelfCare did not show significant differences both in Time $\left(F_{4,209}=3.217 ; p=0.014\right)$ and Gender $\left(F_{1,35}=0.669\right.$; $p=0.419)$, and in the interaction Time $\times$ Gender $\left(F_{4,209}=0.087 ; p=0.986\right)$. Finally, the EQ-5D Thermometer Scale analysis did not show significant differences in Time $\left(F_{4,155}=3.582 ; p=0.008\right)$, and similarly no differences were found between genders $\left(F_{1,66}=0.675 ; p=0.414\right)$, and in the interaction TimexGender $\left(F_{4,155}=0.551 ; p=0.698\right)$.

The involvement in previous treatment and the age of the patients seems to not have produced significant influences on all the analysed dependent variables (no significant $p$ values for all the variables).

All the data are reported as Means \pm SD in Table II with the results of the post-hoc analysis.

\section{Discussion}

ESWT exerted a positive effect in 5 of the 8 analysed scores. In particular, VAS, EQ-5D Mobility, EQ-5D Pain/Discomfort, and EQ-5D Usual Activities scores showed a significant amelioration after 3 months, with no further changes in the successive time-point assessments.

The trend of the VISA-A appears to be different: the VISA-A scores resulted significantly higher in comparison with baseline after 12 months, indicating that
VISA-A required a longer time for a significant modification compared with the VAS and the 3 scores of EQ-5D (12 months instead of 3 months). However, after 24 months, the VISA-A scores showed a further significant improvement compared with T3 and T6. This results also suggests that the positive effects on the VISA-A continued in the longer term.

ESWT produced significant positive effects in reducing pain, and improved the ability of the patients to manage everyday life, as indicated by the significant amelioration of VAS and VISA-A scores respectively. Also, the quality of life and the health status were significantly enhanced after ESWT intervention, as suggested by the overall improvement of EQ-5D scores, with the only exception of Anxiety/Depression and Self-Care dimensions' scores. However, the baseline scores of these two dimensions (see Table 2) resulted substantially low, and they remained low for the whole duration of the follow-up. Consequently, the non-significant modification of these two scores was probably attributable to a low impact of IAT on these 2 dimensions since the baseline assessment.

Another clinically important finding concerns the time necessary to obtain significant benefits on health status and pain relief. In fact, there was a significant improvement at three months after the last session of ESWT in VAS, EQ-5D Pain/Discomfort, and EQ-5D Usual Activities. It took a little longer for the shockwave treatment to have a significant effect on mobility and function as demonstrated by the significant improvement in the EQ-5D Mobility Score at 6 months onwards. Given these results, ESWT can be considered a valid and effective method for the treatment of IAT.

The results of the present study are in accordance with recent meta-analyses performed in 2013, 2014 and in 2017, confirming that ESWT is safe and effective in the non-surgical management of IAT. There is evidence that ESWT is effective in treating IAT 6,18,19. However, the literature also reported that larger sample and high-quality clinical trials and systematic reviews are necessary to demonstrate the efficacy of ESWT, and long term follow-up studies are needed to better define the efficacy of ESWT. In this respect, the ASSERT database plays an important role. In fact, the purpose of ASSERT is exactly to collect high quality and relevant data about the effectiveness of ESWT in patients with IAT in a pragmatic and systematic manner to improve the quality of outcomes and ensure the quality and cost effectiveness of ESWT. ASSERT can monitor the outcomes achieved by practitioners and identify where these fall below an expected performance to inform best practice and additional training requirements.

Some studies have demonstrated that the effectiveness of treatment is dose-related, and that high-energy shock waves from 0.42 to $0.54 \mathrm{~mJ} \cdot \mathrm{mm}^{2}$ can induce tendon lesion and that an energy flux density of more than $0.28 \mathrm{~mJ} / \mathrm{mm}^{2}$ should not be used for treatment of any tendon disorders ${ }^{20}$. In the present study the energy was standardised at no more that 0.28 $\mathrm{mJ} / \mathrm{mm}^{2}$ 
Table II. Results relative to the effects over time with the post-hoc analyses outputs.

\begin{tabular}{|c|c|c|c|c|c|c|c|c|}
\hline \multirow[t]{2}{*}{ Tests } & & \multirow{2}{*}{\begin{tabular}{|l|} 
T0 \\
Means \\
(range) \\
[N] \\
\end{tabular}} & \multirow{2}{*}{\begin{tabular}{|l|} 
T3 \\
$\begin{array}{l}\text { Means } \\
\text { (raange) } \\
\text { [N] }\end{array}$ \\
\end{tabular}} & \multirow{2}{*}{\begin{tabular}{|l|} 
T6 \\
$\begin{array}{l}\text { Means } \\
\text { (range) } \\
{[\mathrm{N}]}\end{array}$ \\
\end{tabular}} & \multirow{2}{*}{\begin{tabular}{|l|} 
T12 \\
Means \\
(range) \\
[N] \\
\end{tabular}} & \multirow{2}{*}{\begin{tabular}{|l|} 
T24 \\
$\begin{array}{l}\text { Means } \\
\text { (range) } \\
{[\mathrm{N}]}\end{array}$ \\
\end{tabular}} & \multirow{2}{*}{$\begin{array}{l}\text { Overall } \\
\text { significance } \\
\text { in time }\end{array}$} & \multirow{2}{*}{$\begin{array}{l}\text { Comparisons } \\
\text { in pair - } \\
\text { significance }\end{array}$} \\
\hline & & & & & & & & \\
\hline \multirow[t]{2}{*}{ VAS } & Scores & $\begin{array}{l}58.80(1- \\
100)[76]\end{array}$ & $\begin{array}{l}32.88 \quad(0- \\
90)[48]\end{array}$ & $\begin{array}{l}32.95(0- \\
100)[40]\end{array}$ & $\begin{array}{l}24.74(0- \\
90)[35]\end{array}$ & $\begin{array}{l}18.16(0- \\
90)[31]\end{array}$ & \multirow[t]{2}{*}{$p<0.0001$} & \multirow[t]{2}{*}{$\begin{array}{l}\text { T0 vs T3, T6, } \\
\text { T12, T24 }\end{array}$} \\
\hline & $\begin{array}{l}\text { Difference } \\
\text { with } \\
\text { baseline } \\
\text { score }\end{array}$ & - & -25.92 & -25.85 & -34.06 & -40.64 & & \\
\hline \multirow[t]{2}{*}{ VISA-A } & Scores & $\begin{array}{l}41.99(0- \\
94)[71]\end{array}$ & $\begin{array}{l}53.70 \quad(5- \\
99)[44]\end{array}$ & $\begin{array}{l}54.32(0- \\
100)[38]\end{array}$ & $\begin{array}{l}66.33(5- \\
100)[33]\end{array}$ & $\begin{array}{l}72.29(0- \\
100)[31]\end{array}$ & \multirow[t]{2}{*}{$p<0.0001$} & \multirow{2}{*}{$\begin{array}{l}\text { T0 vs T12, } \\
\text { T24 } \\
\text { T3 vs T24 } \\
\text { T6 vs T24 }\end{array}$} \\
\hline & $\begin{array}{l}\text { Difference } \\
\text { with } \\
\text { baseline } \\
\text { score }\end{array}$ & - & +11.71 & +12.33 & +24.34 & +30.3 & & \\
\hline \multirow[t]{2}{*}{$\begin{array}{l}\text { EQ-5D } \\
\text { Anxiety/Depression }\end{array}$} & Scores & $\begin{array}{l}1.36 \quad(1- \\
3)[75]\end{array}$ & $\begin{array}{l}1.11(1-2) \\
{[45]}\end{array}$ & $\begin{array}{l}1.18 \quad(1- \\
3)[40]\end{array}$ & $\begin{array}{l}1.12 \quad(1- \\
2)[34]\end{array}$ & $\begin{array}{l}1.10 \quad(1- \\
\text { 2) }[31]\end{array}$ & \multirow[t]{2}{*}{$\begin{array}{l}\text { Not } \\
\text { significant }\end{array}$} & \multirow[t]{2}{*}{-} \\
\hline & $\begin{array}{l}\text { Difference } \\
\text { with } \\
\text { baseline } \\
\text { score }\end{array}$ & - & -0.25 & -0.18 & -0.24 & -0.26 & & \\
\hline \multirow[t]{2}{*}{ EQ-5D Mobility } & Scores & $\begin{array}{l}1.71 \quad(1- \\
3)[75]\end{array}$ & $\begin{array}{l}1.47(1-2) \\
{[45]}\end{array}$ & $\begin{array}{l}1.43(1- \\
2)[40]\end{array}$ & $\begin{array}{l}1.35 \quad(1- \\
\text { 2) }[34]\end{array}$ & $\begin{array}{l}1.35 \quad(1- \\
2)[31]\end{array}$ & \multirow[t]{2}{*}{$p=0.002$} & \multirow[t]{2}{*}{$\begin{array}{l}\text { T0 vs T6, T12, } \\
\text { T24 }\end{array}$} \\
\hline & $\begin{array}{l}\text { Difference } \\
\text { with } \\
\text { baseline } \\
\text { score }\end{array}$ & - & -0.24 & -0.28 & -0.36 & -0.36 & & \\
\hline \multirow[t]{2}{*}{ EQ-5D Pain/Discomfort } & Scores & $\begin{array}{l}2.00 \quad(1- \\
3)[75]\end{array}$ & $\begin{array}{l}1.71(1-3) \\
{[45]}\end{array}$ & $\begin{array}{l}1.68 \quad(1- \\
3)[40]\end{array}$ & $\begin{array}{l}1.56 \quad(1- \\
3)[34]\end{array}$ & $\begin{array}{l}1.52 \quad(1- \\
3)[31]\end{array}$ & \multirow[t]{2}{*}{$p<0.0001$} & \multirow[t]{2}{*}{$\begin{array}{l}\text { T0 vs T3, T6, } \\
\text { T12, T24 }\end{array}$} \\
\hline & $\begin{array}{l}\text { Difference } \\
\text { with } \\
\text { baseline } \\
\text { score }\end{array}$ & - & -0.29 & -0.32 & -0.44 & -0.48 & & \\
\hline \multirow[t]{2}{*}{ EQ-5D Usual Activities } & Scores & $\begin{array}{l}1.80 \quad(1- \\
3)[75]\end{array}$ & $\begin{array}{l}1.47(1-3) \\
{[45]}\end{array}$ & $\begin{array}{l}1.45(1- \\
3)[40]\end{array}$ & $\begin{array}{l}1.29(1- \\
3)[34]\end{array}$ & $\begin{array}{l}1.35(1- \\
3)[31]\end{array}$ & \multirow[t]{2}{*}{$p<0.0001$} & \multirow[t]{2}{*}{$\begin{array}{l}\text { T0 vs T3, T6, } \\
\text { T12, T24 }\end{array}$} \\
\hline & $\begin{array}{l}\text { Difference } \\
\text { with } \\
\text { baseline } \\
\text { score }\end{array}$ & - & -0.33 & -0.35 & -0.51 & -0.45 & & \\
\hline \multirow[t]{2}{*}{ EQ-5D Self-Care } & Scores & $\begin{array}{l}1.11(1- \\
3)[75]\end{array}$ & $\begin{array}{l}1.02(1-2) \\
{[45]}\end{array}$ & $\begin{array}{l}1.00(1- \\
1)[40]\end{array}$ & $\begin{array}{l}1.00(1- \\
\text { 1) }[34]\end{array}$ & $\begin{array}{l}1.00 \quad(1- \\
1)[31]\end{array}$ & \multirow[t]{2}{*}{$\begin{array}{l}\text { Not } \\
\text { significant }\end{array}$} & \multirow[t]{2}{*}{-} \\
\hline & $\begin{array}{l}\text { Difference } \\
\text { with } \\
\text { baseline } \\
\text { score }\end{array}$ & - & -0.09 & -0.11 & -0.11 & -0.11 & & \\
\hline \multirow[t]{2}{*}{$\begin{array}{l}\text { EQ-5D Thermometer } \\
\text { Sc. }\end{array}$} & Scores & $\begin{array}{l}65.28(1- \\
100)[75]\end{array}$ & $\begin{array}{l}77.07(30- \\
100)[45]\end{array}$ & $\begin{array}{l}79.30 \\
(30-100) \\
{[40]} \\
\end{array}$ & $\begin{array}{l}80.91 \\
(40-99) \\
{[34]}\end{array}$ & $\begin{array}{l}77.32 \\
(30-98) \\
{[31]}\end{array}$ & \multirow[t]{2}{*}{$\begin{array}{l}\text { Not } \\
\text { significant }\end{array}$} & \multirow[t]{2}{*}{-} \\
\hline & $\begin{array}{l}\text { Difference } \\
\text { with } \\
\text { baseline } \\
\text { score }\end{array}$ & - & +11.79 & +14.02 & +15.63 & +12.04 & & \\
\hline
\end{tabular}

$p$-value for significance after Bonferroni correction is $<0.006$ 
It has been reported that an increase in the VISA-A between $12^{21,22}$ and $20^{23}$ is clinically relevant. The results of the present study demonstrate that the improvement in pain and function improve over time. Two years post treatment the pain has reduced significantly and the function has improved dramatically, a mean increase of 30 in the VISA-A between the baseline and the score at 24 months.

Comparisons of the different studies are difficult because of substantial variations: ESWT used alone or together with other therapies, the amount of energy employed, the methods of localization of the shock waves, the number of shocks, and the number of sessions used. For example, recently, Rompe et al. found that ESWT alone (radial shock wave therapy) was less efficient than ESWT combined with stretching in improving foot function in patients with chronic plantar heel pain. Another aspect to consider is the difference between high vs low intensity shock wave therapy, and the differences between radial and focused shock wave therapy can have different effects on the treatment of IAT. For this reasons, more highquality and well-conducted studies are necessary. In particular, the creation of a database such as ASSERT could be a valid method for the systematic collection of large amount of data and for the standardization of procedures to obtain strong evidences in this field.

This study is not a randomised controlled trial. However, Level I studies have been conducted in the present field, and have shown that ESWT, when administered according to well established protocols, is safe and effective in the management of the condition at hand. The National Institute for Health and Clinical Excellence (NICE) suggested that the effectiveness of ESWT in "real life" would have needed to be evaluated in a pragmatic fashion, using standardised protocols and well validated clinically relevant outcome measures. The ASSERT protocol is NICE compliant, and satisfies the requirements set out by $\mathrm{NICE}^{24}$.

The fact that many different clinicians were involved in the administration of the treatment, after appropriate certified training and standardisation of the proto$\mathrm{col}$, and that the effects of treatment were evaluated by independent individuals, increases the generalizability of the present findings, and, in this respect, should be considered a major strength of the present study. Also, all patients previously had failed a variety of conservative management means, and this was a major criterion to be recruited in the present study.

In conclusion, when administered in a standardised fashion to an unselected population of patients suffering from insertional Achilles tendinopathy, ESWT therapy is safe and effective in alleviating symptoms for up to 24 months.

\section{Compliance with ethical standards}

\section{Conflict of interest}

All Authors declare no conflict of interest.

\section{Funding}

The ASSERT database has been developed and established through funds provided by Industry (Spectrum Technology UK) and ESPRC grants.

\section{Acknowledgements}

We thank Mr Jim Westwood and Mr Chris Schiel from Spectrum Technology for their support. Mr Nathan Bentley of twotwentyseven London Ltd a creative digital agency developed the ASSERT platform following the direction of Professor Nicola Maffulli and Mrs Gayle Maffulli.

We thank all the clinicians recruiting participants onto the ASSERT database and the participants of ASSERT. Professor Nicola Maffulli developed the concept of ASSERT.

\section{Ethical approval}

All procedures performed in this study involving human participants were in accordance with the ethical standards of the institutional and/or national research committee and with the 1964 Helsinki Declaration and its later amendments or comparable ethical standards.

\section{Informed consent}

Informed consent was obtained from all individual participants included in the study.

\section{References}

1. Wiegerinck Jl, Kerkhoffs GM, van Sterkenburg MN, Sierevelt IN, van Dijk CN. Treatment for insertional Achilles tendinopathy: A systematic review. Knee Surg Sports Traumatol Arthrosc. 2012;21(6):1345-1355

2. Caudell GM. Insertional Achilles Tendinopathy. Clin Podiatr Med Surg. 2017:34(2):195-205.

3. Kearney R, Costa ML. Insertional Achilles Tendinopathy management: A systematic review. Foot Ankle Int. 2010;31 (8):689694.

4. Roche AJ, Calder JD. Achilles tendinopathy: A review of the current concepts of treatment. Bone Joint J.2013;95$\mathrm{B}(10): 1299-1307$.

5. Al-Abbad H, Simon JV. The effectiveness of extracorporeal shock wave therapy on chronic Achilles tendinopathy: A systematic review. Foot Ankle Int. 2013;34(1):33-41.

6. Rompe J, Furia J, Maffulli N. Eccentric loading compared with shock wave treatment for chronic insertional Achilles tendinopathy. A randomized, controlled trial. J Bone Joint Surg Am. 2008;90(1):52-61.

7. Furia JP. High-energy extracorporeal shock wave therapy as a treatment for insertional Achilles tendinopathy. Am J Sports Med. 2006;34(5):733-740.

8. Wang $\mathrm{CJ}$, Huang $\mathrm{H}$, Pai $\mathrm{CH}$. Shock wave-enhanced neovascularization at the tendon-bone junction: An experiment in dogs. J Foot Ankle Surg. 2002;41(1):16-22. 
9. Wang CJ, Wang FS, Yang KD, Weng LH, Hsu CC, Huang CS, et al. Shock wave therapy induces neovascularization at the tendon-bone junction. A study in rabbits. J Orthop Res. 2003;21(6):984-989.

10. Ohtori S, Inoue G, Mannoji C, Saisu T, Takahashi K, Mitsuhashi S, et al. Shock wave application to rat skin induces degeneration and reinnervation of sensory nerve fibres. Neurosci Lett. 2001;315(1-2):57-60.

11. Rompe JD, Hopf C, Nafe B, Bürger R. Low-energy extracorporeal shock wave therapy for painful heel: a prospective controlled single-blind study. Arch Orthop Trauma Sur. 1996; 115(2):75-79.

12. Maffulli G, Hemmings S, Maffulli N. Assessment of the Effectiveness of Extracorporeal Shock Wave Therapy (ESWT) For Soft Tissue Injuries (ASSERT): An Online Database Protocol. Transl Med @ UniSa. 2014;10(10):46-51.

13. Padulo J, Oliva F, Frizziero A, Maffulli N. Muscles, Ligaments and Tendons Journal - Basic principles and recommendations in clinical and field science research: 2016 update. MLTJ. 2016;6(1):1-5.

14. Gerdesmeyer L, Wagenpfeil S, Haake M, Maier M, Loew M, Wörtler K, et al. Extracorporeal Shock Wave Therapy for the Treatment of Chronic Calcifying Tendonitis of the Rotator Cuff: a randomized controlled trial. JAMA. 2003;290(19):25732580.

15. EuroQol-Group. EuroQol: a new facility for the measurement of health related quality of life. Health Policy. 1990;16(3):199-208.

16. Scott J, Huskisson EC. Graphic representation of pain. Pain. 1976;2(2):175-184.
17. Robinson JM, Cook JL, Purdam C, Visentini PJ, Ross J, Maffulli N, et al. The VISA-A questionnaire: a valid and reliable index of the clinical severity of Achilles tendinopathy. Br J Sports Med. 2001;35(5):335-341.

18. Furia JP. Extracorporal shockwave therapy in the treatment of chronic insertional Achilles tendinopathy. Orthopade. 2005 Jun;34(6):571-578.

19. Hart L. Shock-wave treatment was more effective than eccentric training for chronic insertional Achilles tendinopathy. Clin J Sport Med. 2009;19:152-153.

20. Rompe JD, Kirkpatrick CJ, Kullmer K, Schwitalle M, Krischek O. Dose-related effects of shock waves on rabbit tendo Achillis. A sonographic and histological study. J Bone Joint Surg Br. 1998 May;80(3):546-552.

21. de Vos RJ, Weir A, van-Schie HT, Bierma-Zeinstra SM, Verhaar JA, Weinans $\mathrm{H}$, Tol JL. Platelet-rich plasma injection for chronic Achilles tendinopathy: a randomized controlled trial. JAMA. 2010;303:144-149.

22. Sayana MK, Maffulli N. Eccentric calf muscle training in nonathletic patients with Achilles tendinopathy. J Sci Med Sport. 2007;10(1):52-58.

23. Tumilty S, Munn J, Abbott JH, McDonough S, Hurley DA, Baxter GD. Laser therapy in the treatment of Achilles tendinopathy: A pilot study. Photomed and Laser Surg. 2008;26(1):2530.

24. National Institute for Health and Care Excellence (NICE). December 2016: https://www.nice.org.uk/guidance/ipg571/resources/extracorporeal-shockwave-therapy-for-Achillestendinopathy-pdf-1899872103152581. 